\title{
Yaw angle effect on the aerodynamic performance of hatchback vehicle fitted with wing spoiler
}

\author{
Kwang-Yhee Chin a, See-Yuan Cheng a, b, ${ }^{*}$, Shuhaimi Mansor ${ }^{c}$ \\ a Faculty of Mechanical Engineering, Universiti Teknikal Malaysia Melaka, Hang Tuah Jaya, 76100 Durian Tunggal, Melaka, Malaysia \\ b Centre for Advanced Research on Energy, Universiti Teknikal Malaysia Melaka, Hang Tuah Jaya, 76100 Durian Tunggal, Melaka, Malaysia \\ Faculty of Mechanical Engineering, Universiti Teknologi Malaysia, 81310 UTM Skudai, Johor, Malaysia \\ * Corresponding author: cheng@utem.edu.my
}

\section{Article history}

Received 27 February 2019

Revised 28 March 2019

Accepted 21 May 2019

Published Online 25 June 2019

\begin{abstract}
Research on spoiler available to date was mainly done to optimize the performance of spoiler in nonzero yaw condition. However, the effect of spoiler is most needed during cornering to ensure the stability of the vehicle. Therefore, this study aims to inspect the effect of yaw angles change on the aerodynamic performance of the NACA 0018 wing spoiler and the subsequent influence on the flow characteristics of the hatchback vehicle. Computational Fluid Dynamics (CFD) has been applied to model the flow. Comparison between numerically obtained results and experimental data was done to validate the CFD method. The findings show that both the drag coefficient, $\mathrm{Cd}$, and lift coefficient, $\mathrm{Cl}$ have increased with increasing yaw angle. However, the spoiler has performed in favor of reducing the $\mathrm{Cd}$ and $\mathrm{Cl}$ even with increasing yaw angle. The averaged proportion contributions from the spoiler to the overall $\mathrm{Cd}$ and $\mathrm{Cl}$ are $2.7 \%$ and $4.1 \%$, respectively. The other body parts that have contributed to the $\mathrm{Cd}$ and $\mathrm{Cl}$ reductions were the base and slant, and the roof.
\end{abstract}

Keywords: Yaw angle, spoiler, aerodynamics

\section{INTRODUCTION}

During cornering, a vehicle needs sufficient frictional forces in between its tires and the road surface to develop sufficient centripetal force to pass the curve without slip. The frictional forces are directly proportional to the downward forces exerted on the vehicle. In principle, the downward forces depend on the weight of the vehicle and the downward component of the aerodynamic force. Although, it may seem intuitive to increase the weight of the vehicle to enhance the frictional force, but this will not improve the performance of the vehicle during cornering due to the fact that the additional weight will produce additional inertia for which the vehicle will need to overcome. Besides, a heavier vehicle will result in higher fuel consumption rate, which is a disadvantage for both economic and environmental considerations. Therefore, the only viable solution would be to rely on aerodynamic effects.

The aerodynamic effects can be obtained by properly installing the aerodynamic devices on the vehicle. One of the common aerodynamic devices is known as spoiler. In general, there are two types of spoilers, front and rear spoilers. A front spoiler is attached to the bumper while a rear spoiler is usually attached to the trailing edge of the roof for hatchback vehicles. The function of a rear spoiler is, as the name implies, to 'spoil' the smooth airflow passing over a vehicle in order to alter its aerodynamic characteristics, such as to reduce drag and increase downforce.

Spoilers of various kinds had been widely researched (S. Cheng \& S. Mansor, 2017), S. Y. Cheng and S. Mansor (2017), Hu and Wong (2011), Mitra (2010), and Kieffer, Moujaes, and Armbya (2006). To date, numerous studies concerning the optimization of the performance of wing spoilers have been reported in the literature. For example, Tsai, $\mathrm{Fu}$, Tai, Huang, and Leong (2009) have studied the effect of various rear spoiler designs which were of aerofoil profiles on the aerodynamic characteristics of a simplified car model. It shows a reduction in lift. Besides, the study of Kim, Chen, and Shulze (2006) shows that by using a spoiler on a minivan, the lift force can be reduced by $100 \%$ when the minivan is driving at a speed of $108 \mathrm{~km} / \mathrm{h}$. Moreover, the studies conducted by Daryakenari, Abdullah, Zulkifli, Sundararajan, and Sood (2013) and Kodali and Bezavada (2012) have also shown the similar lift reduction tendency produced by the spoilers. Although the studies on optimizing the performance of wing-type spoilers are not uncommon, but most of them are limited to zero degree yaw condition (i.e. simulating a vehicle driving in a straight path). However, during cornering, the effect of spoilers in enhancing the downforce is most needed to ensure drive stability and safety through the curve. Therefore, to address the issue, the main objective of the present study is to investigate the aerodynamic performance of the wing spoiler in yawing conditions.

The paper is organized as follows: the chosen hatchback vehicle model is first introduced together with the features of the spoiler. In addition, the convention of yaw condition is briefly explained. Section II documents the CFD settings and validation of the numerical method. In Section III, the results obtained are being reported and discussed. The paper ends with the conclusion in Section IV.

\section{METHODOLOGY}

\section{Hatchback model and spoiler configuration}

In this study, the Ahmed body, a reference road vehicle model introduced by Ahmed, Ramm, and Faltin (1984) is adopted for simulating the hatchback-type vehicle. The $35^{\circ}$ slant angle of the upper rear section of the model is chosen which is typical for most hatchback vehicles.

The Ahmed body fitted with a rear-roof NACA 0018 wing spoiler with $5^{\circ}$ angle of attack is shown in Fig. 1. The chord length of the wing 
is $69 \mathrm{~mm}$. The chord length was decided based on the measurements done on the wing spoiler of real cars and scaled down based on the dimensions of the Ahmed model.

Meanwhile, in order to avoid highly skewed cells during meshing, the sharp end of the wing has been filleted ( $2 \mathrm{~mm}$ radius). For the same reason, all the sharp edges of the two endplates supporting the wing spoiler were filleted ( $2 \mathrm{~mm}$ radius). For the details of the Ahmed model dimensions, the reader is referred to Ahmed et al. (1984).

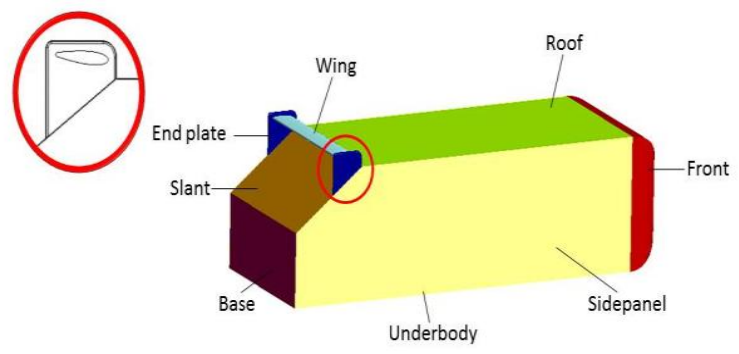

Fig. 1 Ahmed model fitted with a NACA 0018 wing spoiler.

Fig. 2 shows the convention of yaw angles adopted in this study. In the present study, the yaw angles investigated were from $0^{\circ}$ to $12^{\circ}$, at $4^{\circ}$ increment. According to vehicles in real life, the yaw angle will not go beyond of $12^{\circ}$ during cornering. Thus we limit the investigation to $12^{\circ}$ maximum yaw angle.

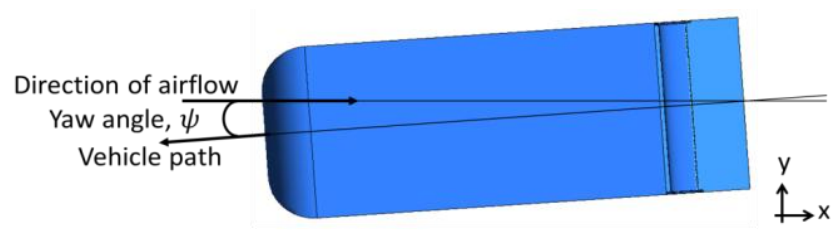

Fig. 2 Convention of yaw angle.

\section{Computational fluid dynamics (CFD) settings}

A numerical simulation method is used in this study to investigate the influence of varying the yaw angle on the aerodynamics of a hatchback model mounted with a NACA 0018 wing spoiler. The commercial CFD software was utilized in the present study. It is a pressure-based solver based on the finite-volume method known as ANSYS Fluent. In fact, ANSYS's CFD solver had been widely used and validated in various applications. For instances, in fields like sports (Jahi, Zawawi, \& Rahman, 2015), medical(Missel, Horner, \& Muralikrishnan, 2010), combustion (Torabmostaedi, Zhang, Foot, Dembele, \& Fernandez, 2013), heat transfer (Alawi, Sidik, \& Tey, 2015; Munir, Mohd Azmi, Razali, \& Tokit, 2012), urban aerodynamics (e.g. Cheng, 2007), and automotive (Shafie, Kamar, \& Kamsah, 2015a, 2015b). In the CFD modelling, the time-averaged, incompressible, continuity and momentum equations are solved as follow:

$$
\begin{gathered}
\frac{\partial \mathrm{u}_{\mathrm{i}}}{\partial \mathrm{x}_{\mathrm{i}}}=0 \\
\rho \mathrm{u}_{\mathrm{j}} \frac{\partial \mathrm{u}_{\mathrm{i}}}{\partial \mathrm{x}_{\mathrm{i}}}=\frac{\partial}{\partial \mathrm{x}_{\mathrm{i}}}\left[-\mathrm{p} \delta_{\mathrm{ij}}+2 \mu \mathrm{S}_{\mathrm{ij}}-\rho \mathrm{u}_{\mathrm{i}}{ }_{\mathrm{i}} \mathrm{u}_{\mathrm{j}}\right]
\end{gathered}
$$

where, $\quad \rho=$ fluid density

$\mathrm{u}=$ time-averaged velocity

$\mathrm{p}=$ time-averaged static pressure

$\mu=$ viscosity of fluid

$\mathrm{S}_{\mathrm{ij}}=$ mean strain tensor rate

$\rho u_{i}^{\prime} u_{j}^{\prime}=$ Reynolds stresses representing the effects of turbulence.

The Reynolds stresses term resulted from performing Reynolds averaging was modelled by the k-epsilon realizable model, which is a two-equation turbulence model. Moreover, the enhanced wall treatment (EWT) has been employed. The EWT models the boundary layer profile in the vicinity of the wall by the wall function when the first grid point is within the log-layer range. As for spatial discretization, secondorder upwind difference scheme has been employed.

At domain's inlet, a uniform velocity $U=40 \mathrm{~m} / \mathrm{s}$ has been imposed. Its turbulence intensity was at $0.2 \%$. The corresponding Reynolds number $(\mathrm{Re})$ was 768,000 based on the model height.

A rectangular flow domain has been adopted. The domain has a cross-sectional area of $1450 \mathrm{~mm}$ x $3890 \mathrm{~mm}$ (height x width). Hence, there was only less than $2 \%$ of blockage ratio obtained, which is far lower compared to the typical accepted 5\% blockage ratio (Hucho \& Sovran, 1993). The inlet and outlet boundaries were respectively located at $1.4 l$ upstream and $11.5 l$ downstream of the model $(l$ is the model length). Meanwhile, the outlet was set as pressure outlet boundary condition with zero gauge pressure. The surfaces of the model and the floor were defined as no-slip wall while the remaining walls were set as symmetry boundary condition.

\section{Meshing}

As shown in Fig. 3, the domain mainly comprises tetrahedral cells in combination with prismatic cells on the no-slip walls. The purpose of the prismatic cells is to improve the resolution of the boundary layer around the model and the ground. The outcome of grid independence test reveals that the mesh with cell number of around 1530368 is sufficiently refined. With the prismatic cells, the thickness of the first node from the model's surface was at $0.5 \mathrm{~mm}$, this corresponds to $\mathrm{y}^{+}$ values ranging from 2 to 53 .

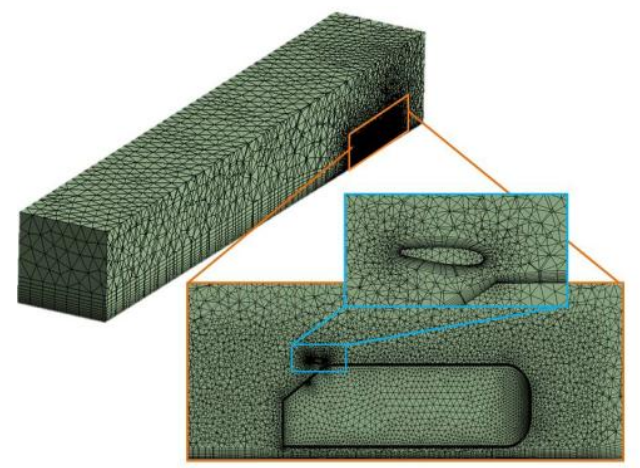

Fig. 3 Mesh density distribution around the Ahmed model with a closedup of prismatic cells around the wing spoiler.

\section{Validation}

In order to validate the numerical method, the present study attempted to reproduce the experimental results by Bello-Millán, Mäkelä, Parras, del Pino, and Ferrera (2016). Fig. 4 compares the drag coefficient $\mathrm{C}_{\mathrm{d}}$ of the Ahmed model at increasing yaw angle obtained by the present CFD method and the experimental work by Bello-Millán et al. (2016). As may be seen, the two curves are in very good agreement (with the maximum difference of $5.2 \%$ at $20^{\circ}$ yaw angle).

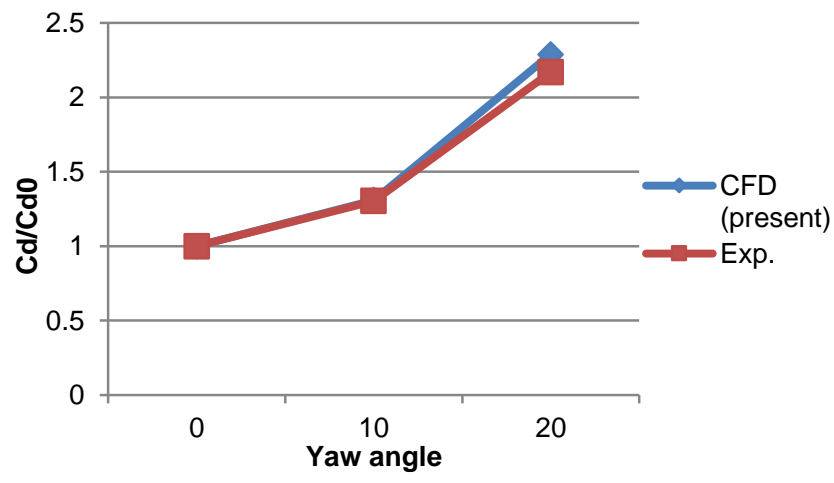

Fig 4 Effect of yaw angle on the $C_{d}$ of Ahmed model obtained by the present CFD and the experimental work by (Bello-Millán et al. (2016)). The $C_{d}$ values by each method are normalized by their respective $C_{d}$ values at $0^{\circ}$ yaw. 
As mentioned earlier, this study only covers the yaw angle range up to $12^{\circ}$. Thus, by interpolation, the corresponding percentage difference between the CFD and experimental results at $12^{\circ}$ yaw angle is only $0.6 \%$. Therefore, we can deduce that the present CFD method is suitable for the investigation.

\section{RESULTS AND FINDINGS}

\section{Effect of yaw angle on $\mathrm{C}_{\mathrm{d}}$ and $\mathrm{C}_{\mathrm{I}}$}

Fig. 5 shows the effect of yaw angle on the total $C_{d}$ and $C_{l}$ of the model. As may be seen, the two aerodynamic force coefficients have risen with increasing yaw angle (Note that the $C_{d}$ is defined as the aerodynamic force component parallel to the longitudinal axis of the model). Thus, the results suggest when the vehicle is no longer travelling in a straight path, its aerodynamic performances will deteriorate.

Fig. 6 shows the effect of yaw angles on the $C_{d}$ and $C_{1}$ of the spoiler. A decreasing trend is observed in the two aerodynamic quantities. In particular, from $0^{\circ}$ to $12^{\circ}$ yaw angle, both the $\mathrm{C}_{\mathrm{d}}$ and $\mathrm{C}_{1}$ have decreased by about $22 \%$ and $43 \%$, respectively. The decreasing trend suggests that the spoiler will actually function better at increasing yaw angle.

However, since the values of the two force coefficients of the spoiler are relatively small compared to the other body parts of the model, thus it failed to alter the increasing trend of the overall $\mathrm{C}_{\mathrm{d}}$ and $\mathrm{C}_{\text {l. }}$. In fact, the proportion contribution of the wing spoiler to the overall $\mathrm{C}_{\mathrm{d}}$ was only $3.24 \%$ at $0^{\circ}$ yaw. As the yaw angle increased to $12^{\circ}$, the proportion contribution of the spoiler has diminished to $2.17 \%$ due to higher increment rate of other body parts.

Meanwhile, in regard to $\mathrm{C}_{1}$, only the underbody and wing spoiler had generated the downforce, whereas the other body parts had generated positive lift. In addition, despite the spoiler's positive influence to the overall $\mathrm{C}_{\mathrm{l}}$, its proportion is only about $4.1 \%$ of the overall downforce generated.

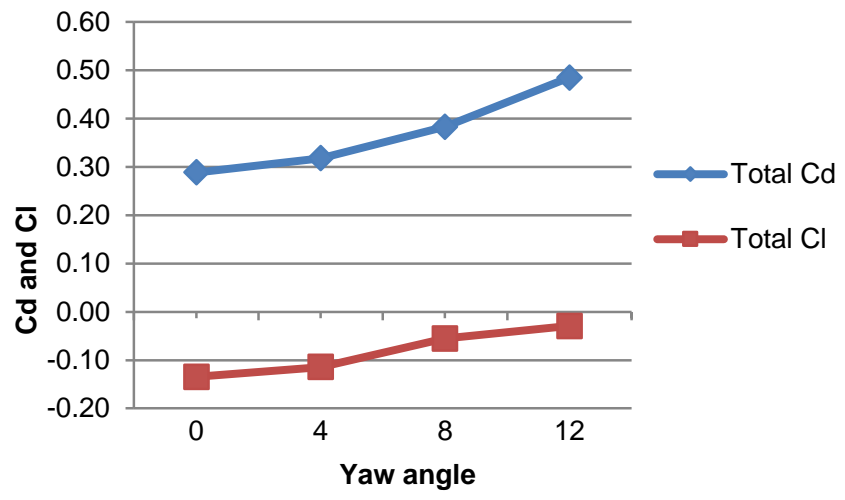

Fig. 5 Effect of yaw angles on $C_{d}$ and $C_{l}$ of Ahmed model with wing spoiler.

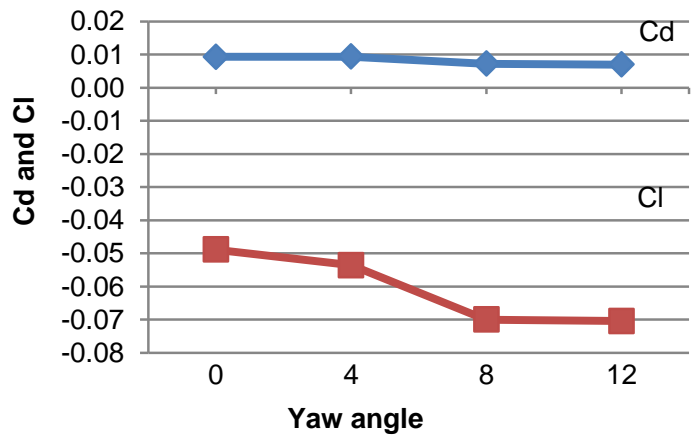

Fig. 6 Effect of yaw angles on $C_{d}$ and $C_{l}$ of rear wing.

Fig. 7 and 8 respectively show the $C_{d}$ and $C_{1}$ of each body part as a function of yaw angle. In Fig. 7 , it is apparent that the main contributors to the increasing $\mathrm{C}_{\mathrm{d}}$ were the base and slant. On the other hand, the front has an opposite, desirable influence on the $C_{d}$ value.
In Fig. 8, the roof has appeared to be the main contributor to the increasing $\mathrm{C}_{1}$ tendency, whereas the underbody has exhibited an opposite influence.

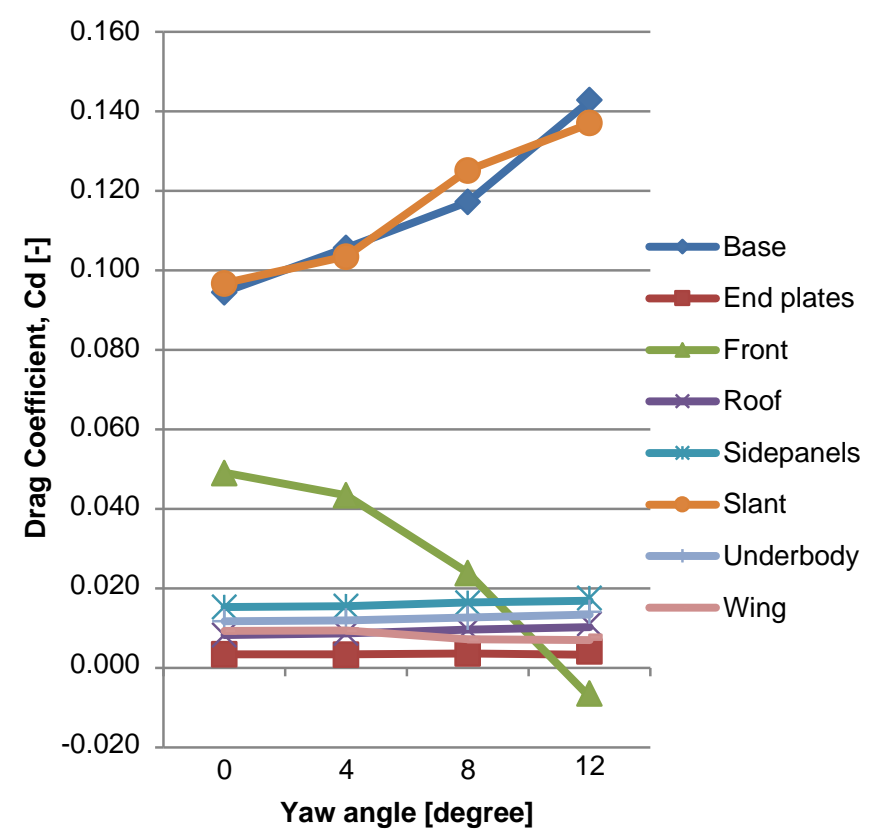

Fig. 7 Contributions of body parts to $C_{d}$ with increasing yaw angles.

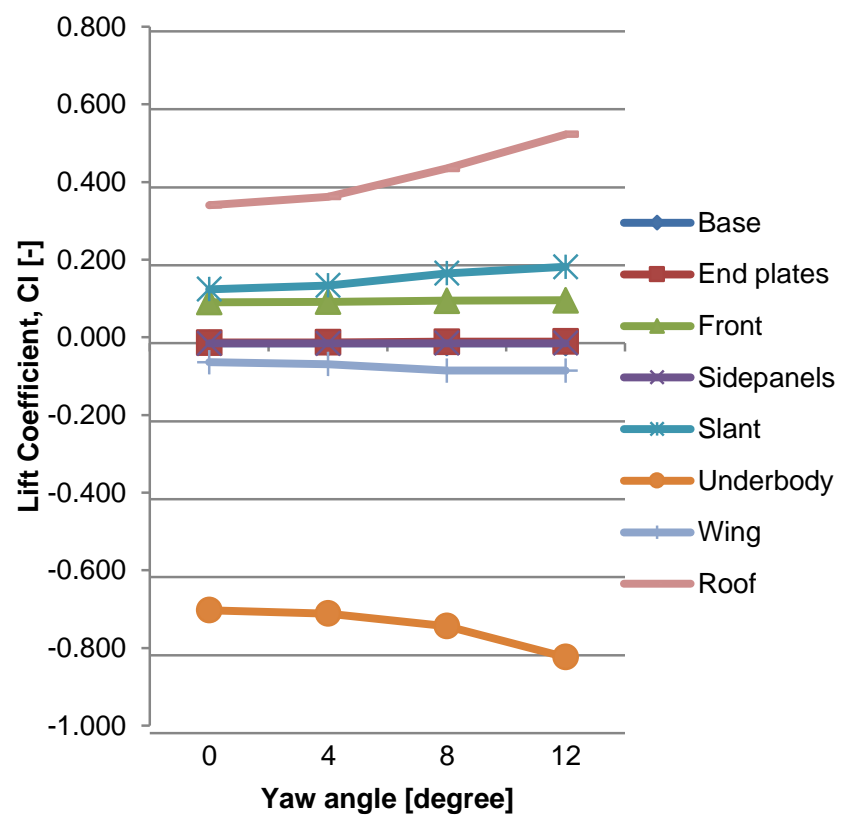

Fig. 8 Contributions of body parts to $C_{\mid}$with increasing yaw angles.

\section{Effect of yaw angle on flow structures}

As shown in Fig. 9, at none-zero yaw angle, four longitudinal vortices (marked A, B, C and D) were developed from the four front corners of the model. This phenomenon is considered reasonable as the front corner edges are of angular shape. Note that the vortices A and D have the counter clockwise rotation whereas the vortices $B$ and $C$ have the clockwise rotation.

As may be seen, the windward vortices $\mathrm{A}$ and $\mathrm{B}$ have each developed a path located on the top and bottom of the model respectively, near the windward side. On the other hand, the leeward vortices $\mathrm{C}$ and $\mathrm{D}$ have each developed a path locating away from the model surfaces. As a result of their closer distance to the model, at increasing yaw angle, the windward vortices A and B could have stronger influence on the surface pressure of the model due to the increasing vortex strength. 
$0^{\circ}$ yaw

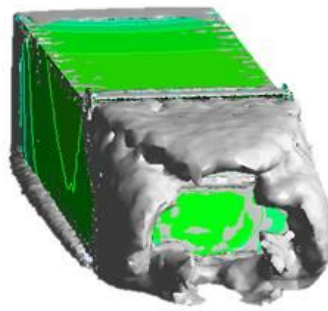

$8^{\circ}$ yaw

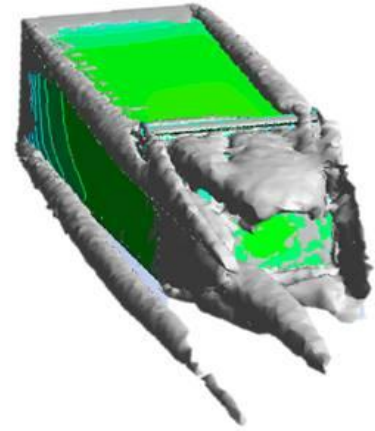

$4^{\circ}$ yaw

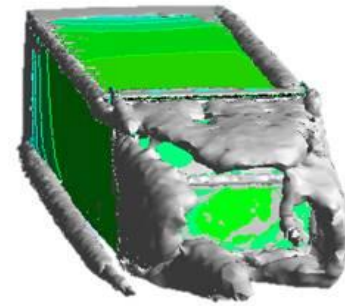

$12^{\circ}$ yaw

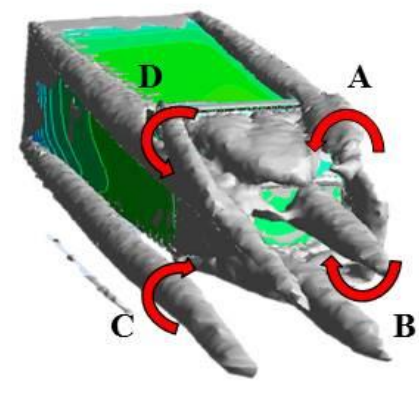

Fig. 9 Effect of yaw angle on body part contributions to $C_{d}$ and $C_{\mid}$.

\section{Physical mechanism}

Fig. 10 compares the surface pressure distribution on the top and bottom parts of the model at different yaw angles. As illustrated, the model have shown the low surface pressure regions (regions in the red boxes) along its top and bottom side edges due to the windward vortices. On the top part of the model, a decrease in the pressure of the roof could cause an increase in the $\mathrm{C}_{1}$. Hence, the roof of the model has shown the increasing $\mathrm{C}_{1}$ trend with increasing yaw angle. In fact, the result in section 3.1 shows that the roof is the main contributor to the increasing trend of the overall $\mathrm{C}_{1}$ with increasing yaw angles.

Meanwhile, for the bottom part of the model, a decrease in the surface pressure will cause the $\mathrm{C}_{1}$ to decrease. Thus, the underbody has exhibited the favourable influence of increasing the downforce with increasing yaw angles.

The reason for the reduction in the $\mathrm{C}_{\mathrm{d}}$ of the front part is illustrated in Fig. 11. As may be seen, the low surface pressure region at the leeward side (i.e. left vertical edge) has become widen with increasing yaw angle. This phenomenon was caused by the flow acceleration near the leeward side corner at higher yaw angle as shown in Fig. 12.

$0^{\circ}$ yaw

Top

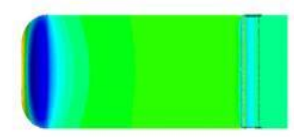

Bottom

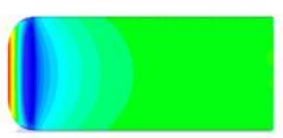

$8^{\circ}$ yaw

Top

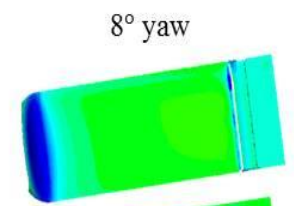

Bottom

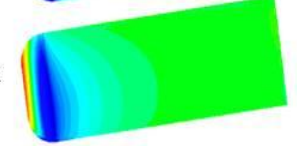

$4^{\circ}$ yaw

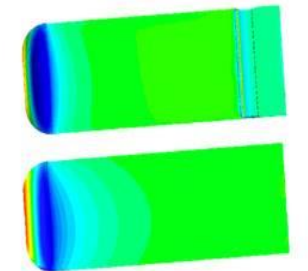

$12^{\circ}$ yaw

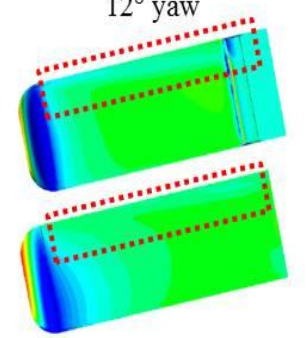

$0^{\circ}$ yaw

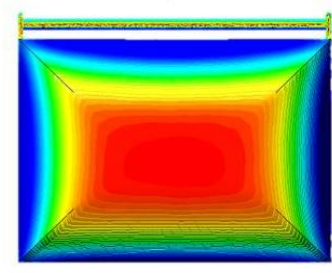

$8^{\circ}$ yaw

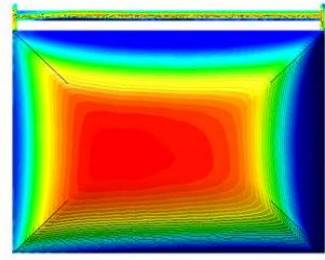

$4^{\circ}$ yaw

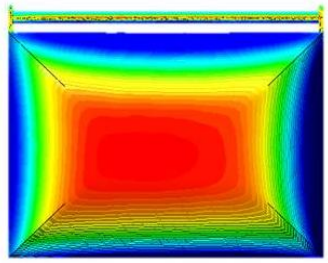

$12^{\circ}$ yaw

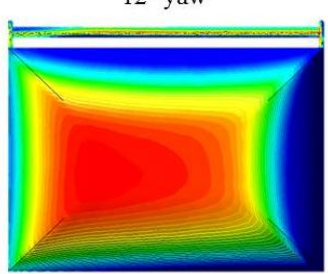

$\mathrm{Cp}$

0.83

0.67

0.50

0.33

0.00

$-0.17$

$-0.33$

$-0.50$

$-0.67$

$-0.83$

$-1.00$

Fig. 11 Surface pressure distribution of the front part at different yaw angles (front view).
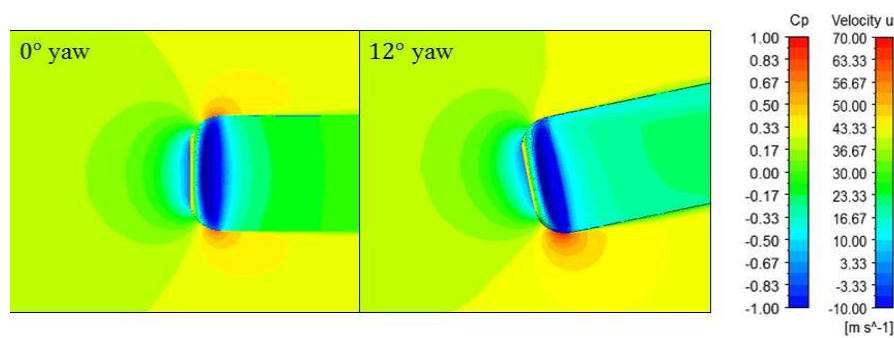

Fig. 12 Yaw angle effect on the velocity distribution near the front part of the model (top view; visualization plane at the mid height of the model).

On the other hand, the surface pressure drop of the slant and base at higher yaw angles (see Fig. 10 and Fig. 13) is the reason why the two body parts had caused the increase in the model's overall $\mathrm{C}_{\mathrm{d}}$ at higher yaw angles. Their pressure drop is associated with the increase in the size of the separation bubbles at the back of the model at higher yaw angle (see Fig. 13).

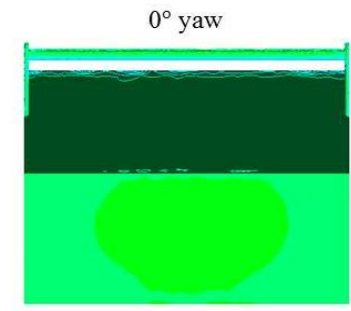

$8^{\circ}$ yaw

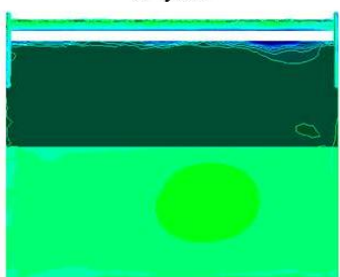

Fig. 13 Surface pressure distributions at different yaw angles (back view).
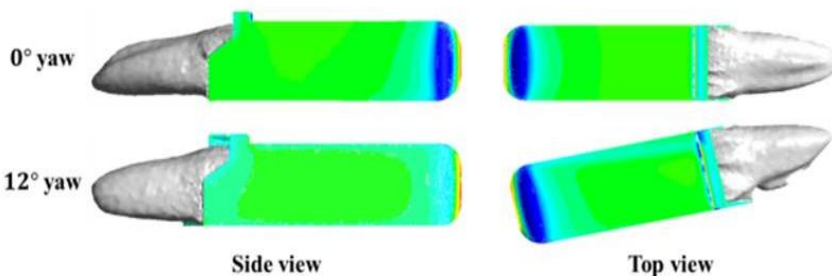

Fig. 14 Separation bubbles formed at different yaw angles.

Fig. 10 Surface pressure distributions at different yaw angles (top view). 


\section{CONCLUSION}

In the present study, a RANS-based CFD modelling has been used to study the influence of varying the yaw angle on the aerodynamic characteristics of an idealized hatchback reference body fitted with a NACA 0018 wing spoiler. The results obtained indicate that both the $\mathrm{C}_{\mathrm{d}}$ and $\mathrm{C}_{\mathrm{l}}$ of the simplified vehicle model have increased with increasing yaw angle. This tendency is deemed unfavourable to fuel economy and drive safety. Although the $\mathrm{C}_{\mathrm{d}}$ and $\mathrm{C}_{\mathrm{l}}$ of the wing spoiler have shown decreasing trends, however, their contribution to the overall $\mathrm{C}_{\mathrm{d}}$ and $\mathrm{C}_{1}$ are small, only with the averaged proportion contributions of $2.7 \%$ and $4.1 \%$ respectively. Hence, the main contributors to the increase of $\mathrm{C}_{\mathrm{d}}$ and $\mathrm{C}_{1}$ had overshadowed the effects brought about by the wing spoiler. The main body parts that have contributed to the increase in $\mathrm{C}_{\mathrm{d}}$ at higher yaw angle are the base and slant, while the rise in $\mathrm{C}_{1}$ is caused by the roof.

\section{ACKNOWLEDGEMENT}

The authors would like to thank Universiti Teknikal Malaysia Melaka (UTeM) and Ministry of Higher Education for supporting this research under FRGS FRGS/1/2015/TK03/FKM/02/F00273.

\section{REFERENCES}

Ahmed, S. R., Ramm, G., Faltin, G. 1984. Some salient features of the timeaveraged ground vehicle wake (ISSN 0148-7191). No. 840300. SAE Technical Paper.

Alawi, O. A., Sidik, N. A. C., Tey, W. Y. 2015. A numerical study of heat transfer to turbulent separation nanofluid flow in an annular passage. Jurnal Teknologi (Sciences \& Engineering), 77(8), 75-82.

Bello-Millán, F., Mäkelä, T., Parras, L., del Pino, C., Ferrera, C. 2016. Experimental study on Ahmed's body drag coefficient for different yaw angles. Journal of Wind Engineering and Industrial Aerodynamics, 157, 140-144.

Cheng, S., Mansor, S. 2017. Rear-roof spoiler effect on the aerodynamic drag performance of a simplified hatchback model. Paper presented at the Journal of Physics: Conference Series, 822(1): 012008.

Cheng, S. Y. 2007. The effect of building shape modification on wind pressure differences for cross-ventilation of a low-rise building. International Journal of Ventilation, 6(2), 167-176.

Cheng, S. Y., Mansor, S. 2017. Influence of rear-roof spoiler on the aerodynamic performance of hatchback vehicle. Paper presented at the
The 2nd International Conference on Automotive Innovation and Green Vehicle (AiGEV 2016), 90: 01027.

Daryakenari, B., Abdullah, S., Zulkifli, R., Sundararajan, E., Sood, A. M. 2013 Numerical study of flow over Ahmed body and a road vehicle and the change in aerodynamic characteristics caused by rear spoiler. International Journal of Fluid Mechanics Research, 40(4), 354-372.

$\mathrm{Hu}, \mathrm{X}$., Wong, T. 2011. A numerical study on rear-spoiler of passenger vehicle. World Academy of Science, Engineering and Technology, 5(9), 18001805.

Hucho, W.-h., Sovran, G. 1993. Aerodynamics of road vehicles. Annual Review of Fluid Mechanics, 25(1), 485-537.

Jahi, T. M., Zawawi, H. I., Rahman, N. A. 2015. Effect of skirt angle and feathers formation on shuttlecock aerodynamics performance. Jurnal Teknologi, 76(8), 95-99.

Kieffer, W., Moujaes, S., Armbya, N. 2006. CFD study of section characteristics of Formula Mazda race car wings. Journal of Mathematical and Computer Modelling, 43(11-12), 1275-2387.

Kim, I., Chen, H., Shulze, R. C. 2006. A rear spoiler of a new type that reduces the aerodynamic forces on a mini-van (ISSN 0148-7191). No. 2006-011631. SAE Technical Paper.

Kodali, S., Bezavada, S. 2012. Numerical simulation of air flow over a passenger car and the influence of rear spoiler using CFD. International Journal of Advanced Transport Phenomena, 1(1), 6-13.

Missel, P. J., Horner, M., Muralikrishnan, R. 2010. Simulating dissolution of intravitreal triamcinolone acetonide suspensions in an anatomically accurate rabbit eye model. Pharmaceutical Research, 27(8), 1530-1546.

Mitra, D. 2010. Effect of relative wind on notch back car with add-on parts. International Journal of Engineering Science and Technology, 2(4), 472 476.

Munir, F. A., Mohd Azmi, M., Razali, N., Tokit, E. M. 2012. The effect of parameter changes to the performance of a triangular shape interrupted microchannel heat sink. Journal Teknologi (Sciences \& Engineering), 58(2), 33-37.

Shafie, N. E. A., Kamar, H. M., Kamsah, N. 2015a. A CFD simulation of PM1 and $\mathrm{CO}$ air contaminants in a bus passenger compartment. Jurnal Teknologi (Sciences \& Engineering), 77(30), 35-39.

Shafie, N. E. A., Kamar, H. M., Kamsah, N. 2015b. Effects of ventilation setups on air flow velocity and temperature fields in bus passenger compartment. Jurnal Teknologi (Sciences \& Engineering), 77(30), 49-53.

Torabmostaedi, H., Zhang, T., Foot, P., Dembele, S., Fernandez, C. 2013. Process control for the synthesis of $\mathrm{ZrO}_{2}$ nanoparticles using FSP at high production rate. Powder Technology, 246, 419-433.

Tsai, C. H., Fu, L. M., Tai, C. H., Huang, Y. L., Leong, J. C. 2009. Computational aero-acoustic analysis of a passenger car with a rear spoiler. Applied Mathematical Modelling, 33(9), 3661-3673. 